\title{
Oral bifosfonat tedavisi görmüş olan bir hastanın dental implant destekli protez ile rehabilitasyonu: Olgu sunumu
}

\author{
Nuray Yılmaz Altıntaş ${ }^{1}$, Emre Balaban ${ }^{1}$, Mehmet Uğur ${ }^{2}$, Subutay Han Altıntaş$^{2}$
}

Selcuk Dent J, 2016; 3: 69-74

Başvuru Tarihi: 27 Nisan 2016 Yayına Kabul Tarihi: 28 Nisan 2016

\begin{abstract}
öz
Oral bifosfonat tedavisi görmüş olan bir hastanın dental implant destekli protez ile rehabilitasyonu: Olgu sunumu
\end{abstract}

Bifosfonatlar kemik metabolizmasında osteoklastik inhibitör etkileri nedeniyle birçok kemik ile ilgili hastalıkta yaygın olarak kullanımaktadır. Son yıllarda intravenöz (iv) ve oral yolla alınan bifosfonatların, ciddi bir yan etkisi olan bifosfonata bağlı çenelerde görülen osteonekroz (BRONJ) hakkında bir çok vaka rapor edilmiştir. BRONJ oluşturma riski yüksek olması nedeniyle iv bifosfonat kullanımı, dental implant uygulamalarında kesin kontraendikasyon olduğu bildirilmiştir. Ancak oral bifosfonat kullanan hastalarda dental implant yapılması ile ilgili öneriler sınırlı verilere dayanmaktadır. Bu olgu raporunda, osteoporoz nedeniyle 3 yıl bifosfonat tedavisi görmüş olan hastanın dental implant destekli protez ile rehabilitasyonu sunulmuştur.

\section{ANAHTAR KELIMELER}

Bifosfonatlar, dental implant, osteonekroz

Bifosfonatlar, osteklastik aktiviteyi ve kemik yapım ve yıkımını azaltması nedeniyle pek çok kemik ile ilgili hastalıkta yaygın olarak kullanılmaktadır (Madrid ve Sanz 2009). İntravenöz (IV) ve oral olmak üzere bifosfonatların iki veriliş yolu bulunmaktadır. IV yolla verilen bifosfonatlar genellikle meme, prostat, ve akciğer kanserinde kemik metastazı mevcudiyetinde ve diğer malign kemik hastalıklarında kullanılmaktadır. Oral bifosfonatlar ise osteoporoz, Paget hastalığı ve osteogenesis imperfekta tedavisinde kullanilurlar (Grant ve ark. 2008).

Illk olarak 2003 yllında Marx (2003) bifosfonat kullanımı ile çene kemiklerinde görülen osteonekroz arasındaki ilişkiye dikkat çekmiştir. Amerikan Oral ve Maksillofasiyal Cerrahi Birliği (AAOMS)'nin 2007 ve 2009 yıllarında bifosfonata bağlı çenelerde görülen kemik osteonekrozu (Bisphosphonate Related Osteonecrosis of the Jaw-BRONJ) ile ilgili bildirge yayınlamışlardır. Bu görüş bildirgelerine göre; daha

\begin{abstract}
The rehabilitation of a patient who received oral bisphosphonate treatment with dental implant supported prosthesis: A case report

Bisphosphonates are widely used in many bone diseases due to their efficient osteoclastic inhibitor effect on bone metabolism. In recent years, numerous cases of bisphosphonate-associated osteonecrosis of the jaw (BRONJ) have been reported as a side effect of both intravenous (IV) and oral therapy regimens. IV administration of bisphosphonates has been considered an absolute contraindication for placement of dental implants due to the increased risk of BRONJ. However, the recommendations were based on limited data about dental implant placement in patients taking oral bisphosphonates. This report documents the rehabilitation of an osteoporotic patient had treated with oral bisphosphonate for 3 years by dental implant supported prosthesis.
\end{abstract}

\section{KEYWORDS}

Biphosphonates, dental implant, osteonecrosis

önce baş boyun bölgesinden radyoterapi almamış, bifosfonat kullanmakta olan veya kullanmış hastaların çenelerinde 8 haftadan daha uzun süredir mevcut ekspoze kemik varlığı ve spontan olarak iyileşememe durumu ile karakterize klinik tablo BRONJ olarak tanımlanmıştır (Advisory Task Force on Bisphosphonate-Related Osteonecrosis of the Jaw, American American Association of Oral and Maxillofacial Surgeons 2007, Ruggiero ve ark 2009). Her ne kadar nekrotik sahalar spontan olarak gelişebilse de, diş çekimlerinin veya önceden yapılmış dento-alveolar cerrahilerin neden olduğu dental travmalar lezyonların gelişmesinde bir risk faktörüdür (Advisory Task Force on BisphosphonateRelated Osteonecrosis of the Jaw, American American Association of Oral and Maxillofacial Surgeons).

BRONJ vakalarında hastanın bifosfonat tedavisinin IV veya oral yolla alması tedavinin prognozu açısından

\footnotetext{
${ }^{1}$ Karadeniz Teknik Üniversitesi Diş Hekimliği Fakültesi Ağız, Diş ve Çene Cerrahisi Anabilim Dalı, Trabzon

${ }^{2}$ Karadeniz Teknik Üniversitesi Diş Hekimliği Fakültesi Protetik Diş Tedavisi Anabilim Dalı, Trabzon
} 
önem kazanır. Oral yolla bifosfonat tedavisi gören hastalarda BRONJ görülme riski ve lezyonların ciddiyeti, iV bisfosfonat kullanan hastaya oranla daha azdır. Ancak yine de her iki tedavi şeklinde de diş çekimleri ve implant cerrahisinde hastalara çok dikkatli yaklaşmak gereklidir (Ruggiero ve ark. 2014).

Kemik hastalıklarının tedavisi için oral yada iv yolla bifosfonat alan hastalarda oral cerrahi prosedürlerin özellikle sert doku augmentasyonu ve implant uygulamalarının güvenilirliği hala tartışmalıdır (Bell ve Bell 2008). AAOMS'un yayınlamış olduğu bildiride özellikle 3 yıldan fazla oral bifosfonat tedavisi gören hastanın, yapılması planlanan cerrahi işlemden 3 ay önce ve 3 ay sonra eğer mümkün ise tedaviye ara verilmesi önerilmiştir. Ayrıca 3 yıldan daha az süre oral bifosfonat kullanmış hastalarda elektif oral cerrahi işlemlerin kontraendike olmadığı bildirilmiştir (Advisory Task Force on Bisphosphonate-Related Osteonecrosis of the Jaw, American American Association of Oral and Maxillofacial Surgeons 2007).

Dental implantlar çene kemiklerine doğru teknikle uygulandığı zaman gösterdiği yüksek başarı oranıyla diş kaybının giderilmesinde çok önemli bir yere sahiptir (Klineberg 2008). İmplantların kemik ile başarılı bir integrasyonu üç fazda gerçekleşir. Birinci faz, osteojenik hücrelerin implant yüzeyine migrasyonun olduğu ve toplandığı osteokondüksiyon fazıdır. İkinci iyileşme fazı, implant yüzeyinde ve önceden var olan kemik arasında yeni kemik formasyonudur. Bu iki iyileşme fazıyla implant yüzeyinde osteogenesis meydana gelmiş olur. Üçüncü iyileşme fazı ise kemik yapım ve yıkımıdır ki bu faz aslında implant yüzeyiyle kontakta olan kemiğin yenilenmesidir (Davies 2003). Bifosfonat kullanımı kemik yapım ve yıkımı anlamlı bir ölçüde azaltmaktadır ve bu implantların osseointegrasyonunda, kemik iyileşmesinin ilk fazında problemlere yol açabileceği öne sürülmüştür (Goss ve ark. 2010). Ancak farklı çalışmalarda 5 yıldan daha kısa süre oral bifosfonat tedavisi gören hastalarda dental implantların güvenli bir işlem olduğu belirtilmiştir (Jeffcoat 2006, Fugazzotto ve ark. 2007, Bell ve Bell 2008).

Bu olgu sunumunda oral bifosfonat tedavisi görmüş hastanın dental implant destekli protez ile rehabilitasyonu sunulmuştur.

\section{OLGU SUNUMU}

60 yaşındaki erkek hasta, total dişsizlik şikayetiyle Karadeniz Teknik Üniversitesi, Diş Hekimliği Fakültesi, Ağız Diş ve Çene Cerrahisi kliniğine başvurdu. Hastanın alınan anamnezinde osteoporoz, diabetus mellitus ve hipertansiyon hikayesi olduğu öğrenildi. Diabetus mellitus tedavisi nedeniyle oral antidiyabetik, hipertansiyon tedavisi için ise amilodipin türevi kalsiyum kanal blokeri kullandığı tespit edildi. Osteoporoz tedavisi için ise hastanın başvurduğu tarihten 1 sene öncesinde risedronat (Actonel 75mg tab; Sanofi Aventis) kullandığı ve bu tedavisinin 3 yıl sürdüğü öğrenildi.

Hastanın yapılan klinik ve radyografik muayenesinde intraoral herhangi bir patolojik durum gözlenmedi (Resim 1). Karadeniz Teknik Üniversitesi, Diş Hekimliği Fakültesi Protetik Diş Tedavisi Anabilim Dalı ile yapılan konsültasyon sonucu hastaya maksillada 4, mandibulada ise 5 adet implant yapılmasına karar verildi. Üst çenede implant destekli barlı protez, alt çene için ise implant üstü hibrit protez plandı. Hastaya daha önceden kullandığı ilacın çenelerdeki yan etkileri, operasyon sonrası oluşabilecek iyileşme zorlukları anlatıldı ve tedavi onamı alındı.

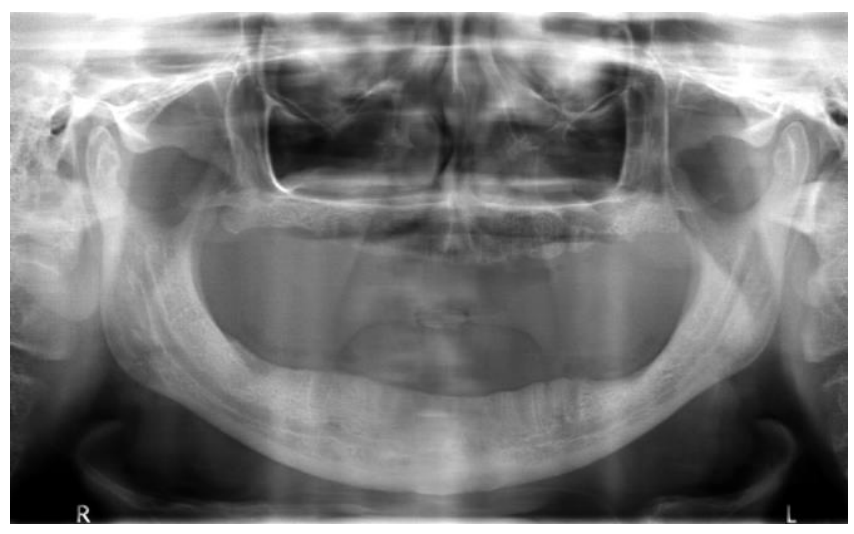

Resim 1.

Operasyon öncesi radyografik görünüm

Hastanın operasyon öncesinde proflaktik olarak 5 gün boyunca antibiyotik (amoksisilin+klavulonik asit) ve ağız gargarası (benzidamin $\mathrm{HCL}+$ klorheksidin glukonat) kullanması uygun görüldü. Lokal anestezi altında yapılan insizyonlar sonrası mukoperiostal flep eleve edildi. Dental implant yuvaları üreticinin talimatları doğrultusunda açıldı ve dental implantlar (İmplance, AGS Medikal, İstanbul, Türkiye) hazırlanan yuvalara yerleştirildi. Kanama kontrolü yapıldı ve flep 3/0 vikril sütur ile primer olarak kapatıldı. Cerrahi işlemden sonra antibiyotik (amoksisilin+klavulanik asit), analjezik-antienflamatuar (deksketoprofen), ağız gargarasından (benzidamin $\mathrm{HCL}+$ klorhesidin glukonat) oluşan standart bir reçete önerildi.

Bir hafta sonra yapılan klinik muayenede mukozada ekspoz ya da dehisens gözlenmedi ve primer yara iyileşmesinin sorunsuz olduğu izlendi. Hasta 1 ay arayla kontrollere çağrıldı ve bu kontrollerde klinik olarak osteonekroz açısından muayene edildi. Yapılan kontrollerde herhangi bir patoloji tespit edilmedi. 3. ay ve 6. ay takibinde ortopantomografi ile radyografik inceleme yapıldı ve implantların çevresinde ve 
apikalinde herhangi bir patoloji gözlenmedi (Resim 2). Hastanın iyileşme başlıkları 6. ay kontrol seansında yerleştirildi. Yumuşak doku iyileşmesi tamamlandıktan sonra protetik tedavi aşamasına geçildi.

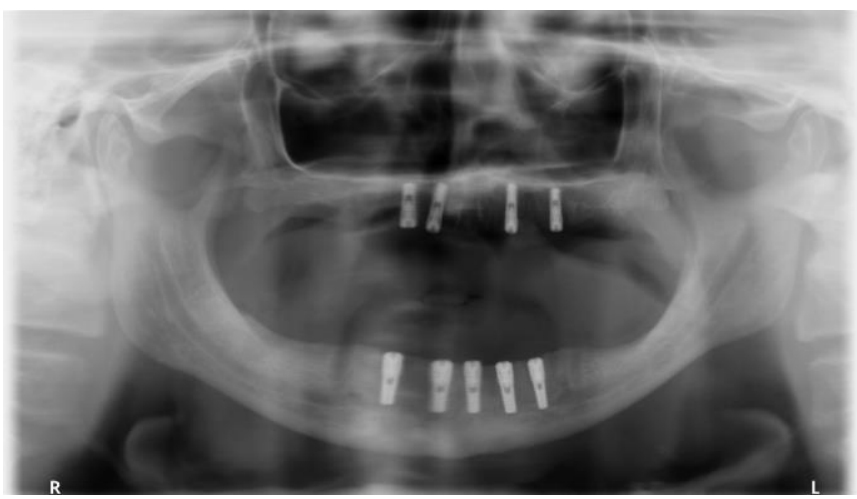

Resim 2

Dental implantların yerleştirilmesinden 6 ay sonra radyografik görünüm

Üst ve alt çenenin anatomik ölçüsü irreversible hidrokolloid ölçü maddesi (Phase Plus, Zhermack, Badia Polesine, RO, İtalya) ile alınarak otopolimerizan akrilik rezinden (Meliodent; Heraeus Kulzer $\mathrm{GmbH}$, Hanau, Almanya) kişisel kaşık yapıldı. Fonksiyonel ölçü alınmadan önce octa sistem abutmentlar (İmplance, AGS Medikal, İstanbul, Tükiye) implantlara $30 \mathrm{Ncm}$ olacak şekilde torklanarak vidalandı (Resim 3). Octa sisteme ait ölçü kopingleri octa sistem abutmentlara vidalandı. Fonksiyonel ölçüler, açık kaşık tekniğine uygun olarak hazırlanan kişisel kaşıklarla elastomerik ölçü maddesi (Optosil Comfort Putty, Heraeus Kulzer GmbH, Almanya, Xantopren L blue, Heraeus Kulzer GmbH, Almanya) kullanılarak implantların ölçüsü alındı ve tip IV dental alçıdan (Hera Moldano, Heraeus Kulzer, Hanau, Almanya) model elde edilerek ölçü postları modele transfer edildi. Üst çene implant destekli barlı protez ve alt çene hibrit protez yapımı için döküm alt yapıları hazırlandı. Hasta ağzında döküm alt yapıların pasif uyumu kontrol edildi. Dikey boyut belirleme işlemi yapıldıktan sonra diş dizimi ve provası yapıldı. Dişli prova sonrası akril tepimi yapıldı. Tesviye ve polisaj işlemlerinden sonra oklüzal uyumlama yapılarak protezler hasta ağzına takıldı (Resim 4). Hem üst çene hem de alt çene implant destekli protezler olduğu için protetik restorasyonlarda parsiyel grup fonksiyonlu oklüzyon tipi sağlandı. Hastaya üst protezlerini çıkarıp temizleyebileceği, alt protezlerinin periyodik kontrollerde tarafımızdan çıkarılabileceği açıklandı. Gerekli hijyen bilgileri sözlü ve uygulamalı olarak anlatıldı. Ara yüz fırçası ve diş ipi kullanımı gösterildi.

Protetik restorasyonlar uygulandıktan sonra hastanın 1., 3. ve 6. ayda klinik ve radyolojik muayenesi yapıldı. Çenelerde ve implantlarda herhangi bir komplikasyon izlenmedi (Resim 5).

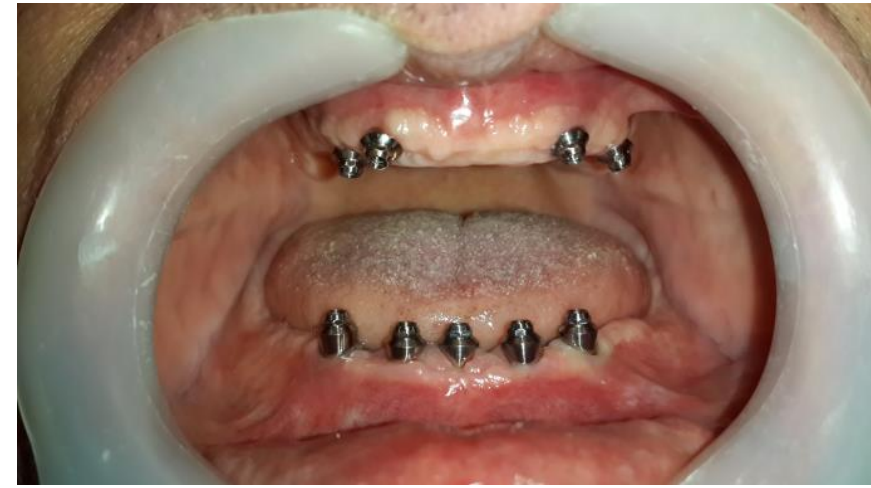

Resim 3.

Octa sistem abutmentların ağız içi görüntüsü

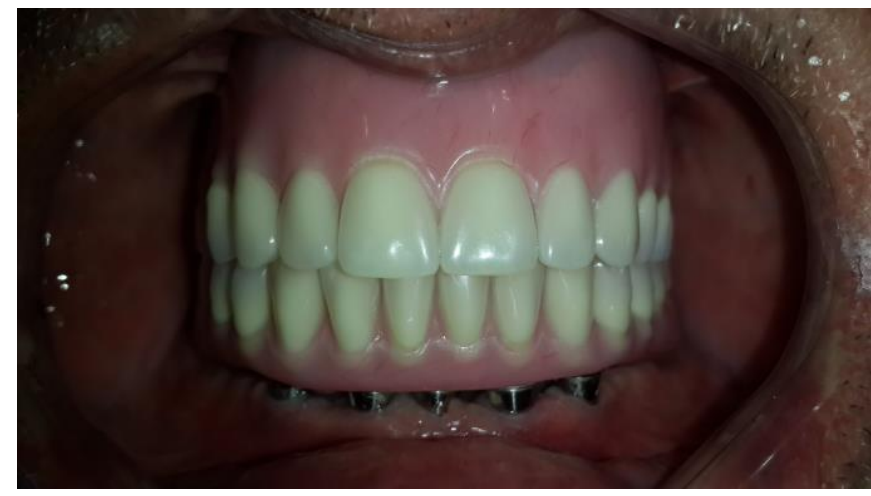

Resim 4.

Dental implant destekli protezlerin ağız içi görüntüsü

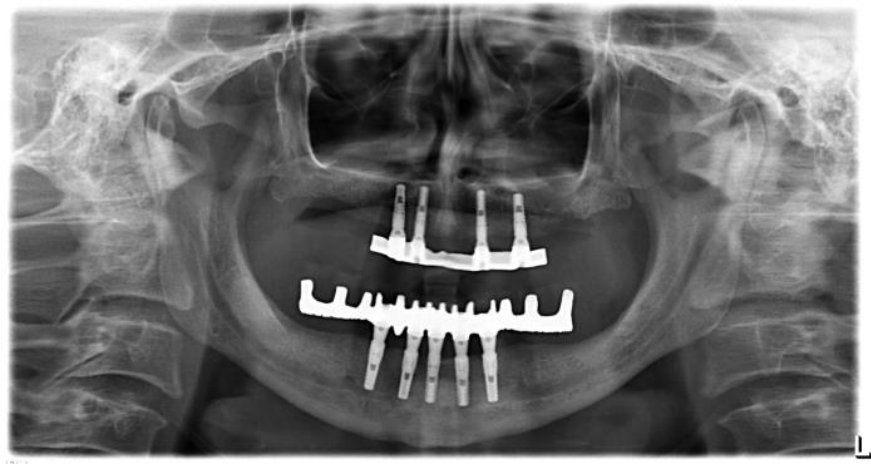

Resim 5.

Protetik rehabilitasyon sonrası radyografik görünüm

\section{TARTISSMA}

IV yolla bifosfonat tedavisi uygulanan hastalarda dental implant yerleştirilmesini de içeren oral cerrahi işlemler, BRONJ gelişmesi için büyük bir risk faktörüdür. Dental implant uygulamaları sonrasında izlenen BRONJ vakaları büyük ölçüde kanser sebebiyle iv yolla bifosfonat tedavisi gören hastalarda tespit edilmiştir 
(Ruggiero ve ark. 2004). Bu nedenle AAOMS tarafından yayımlanan güncel bildirgede, iV bifosfonat kullanan kanser hastalarında dental implant uygulamaları kontraendikasyon olarak nitelendirilmiştir (Ruggiero ve ark. 2014). Her ne kadar oral bifosfonat kullanan hastalarda, oral cerrahi işlemler BRONJ oluşumunda büyük risk olarak kabul edilse de, bu hastalarda dental implant tedavileri için kesin kontraendikasyon yoktur (Assael 2009). Bu konu ile ilgili birçok derleme çalışmasında da oral bifosfonat tedavisi ile implant kayıpları arasında neden-sonuç ilişkisi tam olarak ortaya konamamıştır (Bedogni ve ark. 2010). Ancak klinisyenler, hem iv hem de oral bifosfonat kullanan hastalarının implant kayıplarında ve geç yara iyileşmesinde yüksek risk gruplarında olduklarını unutmamalılardır.

Wang ve ark. (2007) 10 yıldan fazla oral bifosfonat kullanan ve operasyon öncesi bifosfonata ara verilmeyen hastada dental implant uygulaması sonrası osteonekroz tespit etmişlerdir. Literatürde bu çalışmada olduğu gibi oral bifosfonat terapisi sonrası implant bölgesinde komplikasyonlar bildirilmiştir (Marx ve ark. 2007, Brooks ve ark. 2007, Bedogni ve ark. 2010). Bu çalışmaların ortak yönü, oral bifosfonat tedavisinin ortalama 5.5 ylın üzerinde olmasıdır.

Madrid ve Sanz'ın (2009) yapmış olduğu derlemede 1 ile 4 yıl arasında oral bifosfonat kullanan ve dental implant ile rehabilite edilmiş hastalarda çenelerin osteonekrozuna rastlanmamıştır. Bu yazarlara göre implant yerleştirilmesi oral bifosfonat alan hastalarda güvenli bir prosedürdür (Madrid ve Sanz 2009). Benzer bir çalışmada, 42 hasta retrospektif olarak değerlendirildiğinde, implantlarda \%95 başarı oranına ulaşılmış ve hiç bir hastada BRONJ meydana gelmemiştir (Bell ve Bell 2008). Kasai ve ark. (2009), oral bifosfonat kullanmış ve dental implant uygulanan kadın hastalarda, bifosfonat tedavisi görmemiş kadın hastaların implant başarı oranlarını karşılaştırmışlardır. Oral bifosfonat kullanmış olan hastalarda başarı oranı \% 86 , kontrol grubunda ise bu oran \%95 olarak bildirilmiştir. Ancak hiçbir hastada bifosfonatla ilişkili osteonekroz tespit edilmemiştir. Çalışmacılar bu sonuca dayanarak, bifosfonat kullanan hastalarda; bifosfonat kullanımına cerrahi işlemden önce ara verilmesi, preoperatif antibiyotik uygulaması, mukozanın primer olarak kapatılması gibi önlemler alınması gerektiğini ifade etmişlerdir (Kasai ve ark. 2009). Bu olgu sunumunda, dental implant tedavisi öncesi hastanın 3 sene devam eden bifosfonat terapisi 1 sene öncesinde sonlandırımıştı. Hastamızda operasyon sonrası iyileşmede herhangi bir komplikasyon izlenmedi ve protez yüklemesi sonrası 6 aylık takip sürecinde implant bölgelerinde bifosfonat terapisi ile ilişkili osteonekroz tespit edilmedi. dental implant uygulanması planlanan hastalar ile ilgili önlemleri ayrıntılı bir şekilde belirtmişlerdir. Bu çalışmaya göre, 3 yıldan daha az süredir bifosfonat kullanan hastalarda veya bifosfonat tedavisi öncesinde dental implant uygulamasında sakınca olmadığı belirtilmiştir. Ancak 3 yıldan daha uzun süredir bifosfonat kullanımının veya beraberinde kortikosteroid kullanımının, dental implant uygulamasına da içerecek oral cerrahi işlemlerde, BRONJ açısından risk oluşturacağını ifade edilmiştir. $\mathrm{Bu}$ nedenle bu hastalarda oral cerrahi işlemler öncesinde, kemik yapım yıkımının bifosfonatlar tarafından baskılanmasının göstergesi olan serum C-terminal telopeptid (CTX) değerinin önemini vurgulanmıştır. Bu değerin $100 \mathrm{pg} / \mathrm{ml}$ olmasının cerrahi işlem öncesinde bu hastalarda BRONJ açısından risk teşkil edeceği bildirilmiştir. Böyle bir durumda hastanın doktoruyla bu konu konsülte edilmeli ve hastanın sistemik durumunun değerlendirilerek, cerrahi işlem öncesi bifosfonat tedavisine 4-6 ay arasında ara verilmesini önerilmiştir (Marx ve ark. 2007).

Bifosfonat kullanan hastalarda BRONJ oluşum mekanizması tam olarak açıklanamamaktadır ancak uyumlu olmayan haraketli protezler gibi risk faktörleri BRONJ'un gelişiminde önemli rol oynamaktadır (Ruggiero ve ark. 2014). Çalışmalarda intravenöz bifosfonat tedavisi gören hastalarda haraketli protez kullanmanın BRONJ riskini artırdığı bildirilmiştir (Khan ve ark. 2015, Kyrgidis ve ark. 2008). AAOMS'un yayınlamış olduğu bildiride parsiyel veya total kullanan hastalarda, özellikle lingual bölgede, protez kaynaklı mukoza travmasına dikkat edilmesi önerilmiştir (Ruggiero ve ark. 2014). $\mathrm{Bu}$ olguda, hasta konforunun artırıması amacıyla dental implant destekli protez yapılması uygun görüldü. Yukarda belirtilen risk faktörlerini elimine etmek için alt çenede implant destekli sabit hibrit protez, üst çenede ise implant destekli barlı protez tercih edildi.

\section{SONUÇ}

Oral bifosfonat kullanan hastalarda dental implant uygulamaları sonrası BRONJ gelişimi düşük bir risk olsa da bu konu hakkında kesin bir görüş birliği bulunmamaktadır. Oral bifosfonat kullanan hastalarda dental implant tedavisi planlanırken, hasta uzun dönem implant kayıpları ve BRONJ meydana gelme riski yönünden bilgilendirilmeli, doktoruyla konsültasyon yapılmalı ve mümkün ise ilaca ara verilmelidir. Ayrıca bu hastalar düzenli olarak uzun süre takip edilmelidir. Oral bifosfonatlar ve dental implant uygulamalarını inceleyen uzun dönem takipli çalışmalara intiyaç vardır. 


\section{KAYNAKLAR}

Advisory Task Force on Bisphosphonate-Related Osteonecrosis of the Jaw, American American Association of Oral and Maxillofacial Surgeons, 2007. American Association of Oral and Maxillofacial Surgeons position paper on bisphosphonate-related osteonecrosis of the jaws. J Oral Maxillofac Surg, 65, 369-376.

Assael LA, 2009. Oral bisphosphonates as a cause of bisphosphonate-related osteonecrosis of the jaws: clinical findings, assessment of risks, and preventive strategies. J Oral Maxillofac Surg, 67, 35-43.

Bedogni A, Bettini G, Totola A, Saia G and Nocini PF, 2010. Oral bisphosphonate-associated osteonecrosis of the jaw after implant surgery: a case report and literature review. J Oral Maxillofac Surg, 68, 1662-1666.

Bell BM and Bell RE, 2008. Oral bisphosphonates and dental implants: a retrospective study. J Oral Maxillofac Surg, 66, 1022-1024.

Brooks JK, Gilson AJ, Sindler AJ, Ashman SG, Schwartz KG and Nikitakis NG, 2007. Osteonecrosis of the jaws associated with use of risedronate: report of 2 new cases. Oral Surg Oral Med Oral Pathol Oral Radiol Endod, 103, 780-786.

Davies JE, 2003.Understanding peri-implant endosseous healing. J Dent Educ, 67, 932-949.

Fugazzotto PA, Lightfoot WS, Jaffin R and Kumar A, 2007. Implant placement with or without simultaneous tooth extraction in patients taking oral bisphosphonates: postoperative healing, early follow-up, and the incidence of complications in two private practices. J Periodontol, 78, 1664-1669.

Goss A, Bartold M, Sambrook P and Hawker P, 2010. The nature and frequency of bisphosphonateassociated osteonecrosis of the jaws in dental implant patients: a South Australian case series. J Oral Maxillofac Surg, 68, 337-343.

Grant BT, Amenedo C, Freeman K and Kraut RA, 2008. Outcomes of placing dental implants in patients taking oral bisphosphonates: a review of 115 cases. J Oral Maxillofac Surg, 66, 223-230.

Jeffcoat MK, 2006. Safety of oral bisphosphonates: controlled studies on alveolar bone. Int $\mathrm{J}$ Oral Maxillofac Implants, 21, 349-353.
Kasai T, Pogrel MA and Hossaini M, 2009. The prognosis for dental implants placed in patients taking oral bisphosphonates. J Calif Dent Assoc, 37, 39-42.

Khan AA, Morrison A, Hanley DA, Felsenberg D, McCauley LK, O'Ryan F, Reid IR, Ruggiero SL, Taguchi A, Tetradis S, Watts NB, Brandi ML, Peters E, Guise T, Eastell R, Cheung AM, Morin SN, Masri B, Cooper C, Morgan SL, Obermayer-Pietsch B, Langdahl BL, Al Dabagh R, Davison KS, Kendler DL, Sandor GK, Josse RG, Bhandari M, El Rabbany M, Pierroz DD, Sulimani R, Saunders DP, Brown JP and Compston J, 2015. Diagnosis and management of osteonecrosis of the jaw: a systematic review and international consensus. J Bone American Society Bone and Mineral Res, 30, 323.

Klineberg I, 2008. Oral implant rehabilitation: a state-ofthe art overview of case management. Aust Dent J, 53, S1-S1.

Kyrgidis A, Vahtsevanos K, Koloutsos G, Andreadis C, Boukovinas I, Teleioudis Z, Patrikidou A and Triaridis $\mathrm{S}, 2008$. Bisphosphonate-related osteonecrosis of the jaws: a case-control study of risk factors in breast cancer patients. J American Society of Clinical Oncol, 26, 4634-4638.

Madrid C and Sanz M, 2009. What impact do systemically administrated bisphosphonates have on oral implant therapy? A systematic review. Clin Oral Implants Res, 20 Suppl 4, 87-95.

Marx RE, 2003. Pamidronate (Aredia) and zoledronate (Zometa) induced avascular necrosis of the jaws: a growing epidemic. J Oral Maxillofac Surg, 61, 11151117.

Marx RE, Cillo JE, Jr. and Ulloa JJ, 2007. Oral bisphosphonate-induced osteonecrosis: risk factors, prediction of risk using serum CTX testing, prevention, and treatment. J Oral Maxillofac Surg, 65, 2397-2410.

Ruggiero SL, Dodson TB, Assael LA, Landesberg R, Marx RE and Mehrotra B, 2009. American Association of Oral and Maxillofacial Surgeons position paper on bisphosphonate-related osteonecrosis of the jaws-2009 update. J Oral Maxillofac Surg, 67, 2-12.

Ruggiero SL, Dodson TB, Fantasia J, Goodday R, Aghaloo T, Mehrotra B and O'Ryan F, 2014. American Association of Oral and Maxillofacial Surgeons position paper on medication-related osteonecrosis of the jaw-2014 update. J Oral Maxillofac Surg, 72, 1938-1956. 
Ruggiero SL, Mehrotra B, Rosenberg TJ and Engroff SL, 2004. Osteonecrosis of the jaws associated with the use of bisphosphonates: A review of 63 cases. J Oral Maxil Surg, 62, 527-534.

Wang HL, Weber D and McCauley LK, 2007. Effect of long-term oral bisphosphonates on implant wound healing: literature review and a case report. J Periodontol, 78, 584-594.

\section{Yazışma Adresi:}

Yrd. Doç. Dr. Nuray YILMAZ ALTINTAŞ

Karadeniz Teknik Üniversitesi

Diş Hekimliği Fakültesi

Ağız, Diş ve Çene Cerrahisi A.D.

61080 Trabzon, Türkiye

Tel : +90462 3774729

Faks : +904623253017

E-mail: dtnurayilmaz@yahoo.com 